Please send trade news information and illustrations to Arveen Bajaj at the BDJ, 64 Wimpole Street, London W1G 8YS. Trade news is supplied as a service to the reader and does not imply endorsement by the BDJ. Normal and prudent research should be exercised before purchase of use of any product mentioned.

\section{TRADE NEWS \\ WHAT'S NEW}

\section{New luting composite}

Multilink is the new universal luting composite from Ivoclar Vivadent who claim it eliminates the need for both separate acid etching and light-curing.

The self-curing material has been specially formulated for luting in clinical situations where light access can be difficult, for example, the placement of indirect restorations made of metal, metal-ceramics or opaque all-ceramics, and where high bond strengths and tight marginal seals are desired. The adhesive bond is achieved with the help of the self-etching and selfcuring Multilink Primer A/B.

Multilink is supplied in a double syringe, is easy to mix and has a creamy consistency. The material exhibits high initial bonding values on enamel and dentine and cures quickly and reliably in just two to three minutes.

The composite matrix of Multilink is based on that of the tried and tested Variolink II luting system from Ivoclar Vivadent. Multilink together with Variolink II, which is recommended for cementing highly aesthetic restorations, offer a suitable luting composite for the entire spectrum of adhesive indications.

Reader response number 51

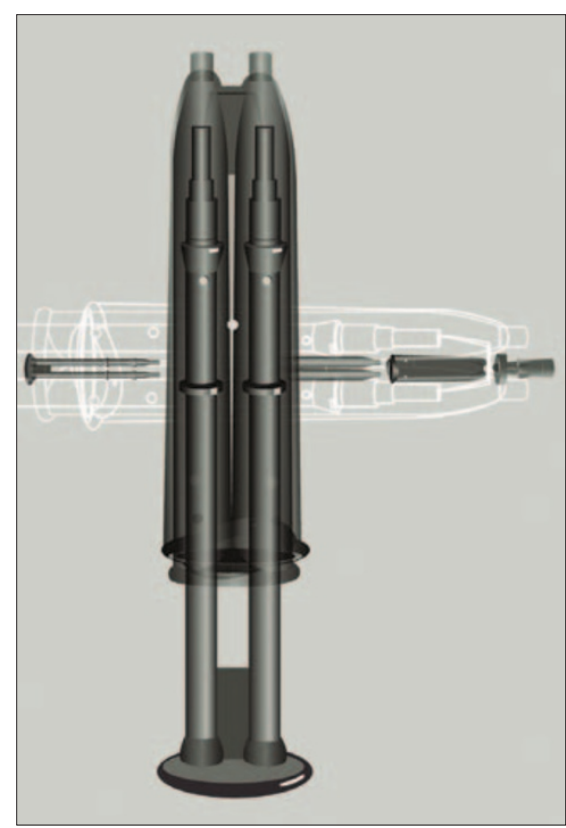

\title{
Cleaner tongues
}

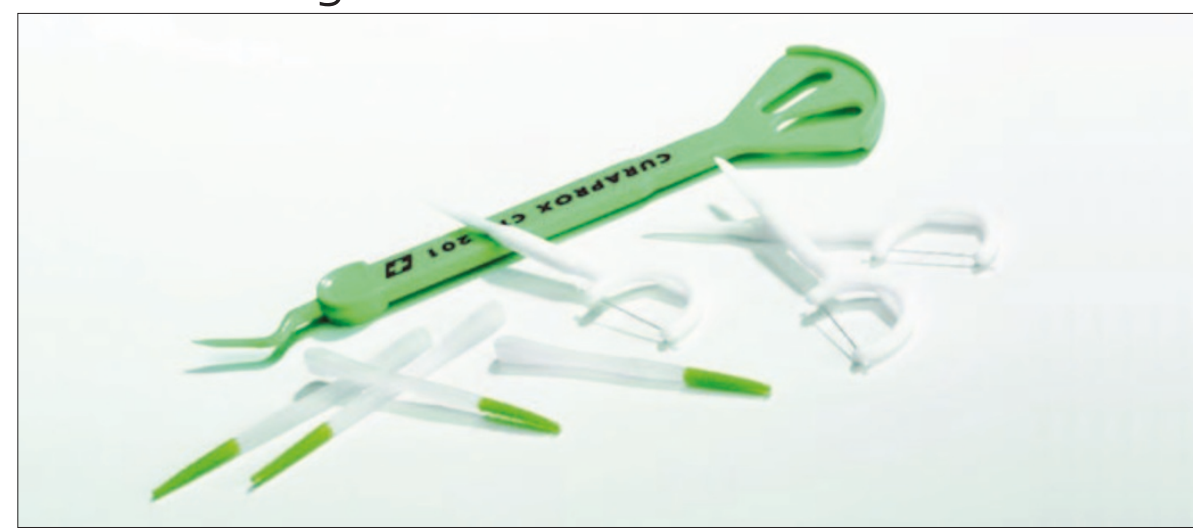

Curaprox has developed a specific tool to tackle tongue cleaning - the 2 in 1 Tongue Scraper. Also incorporating a toothpick, the Tongue Scraper is a scraping ridge with both smooth and serrated edges, which helps to eliminate the risk of gagging.

Curaprox claims that clearing the build up of bacteria from the ridges of the dorsal surface of the tongue combats halitosis, helps to prevent periodontal disease and dental caries and also sharpens taste sensations.

Also available as part of the range of oral hygiene aids from Curaprox is the Brushpic, a strong yet fine nylon toothpick with a flocked tip, and the Flosspic, a toothpick with integrated dental floss Reader response number 50

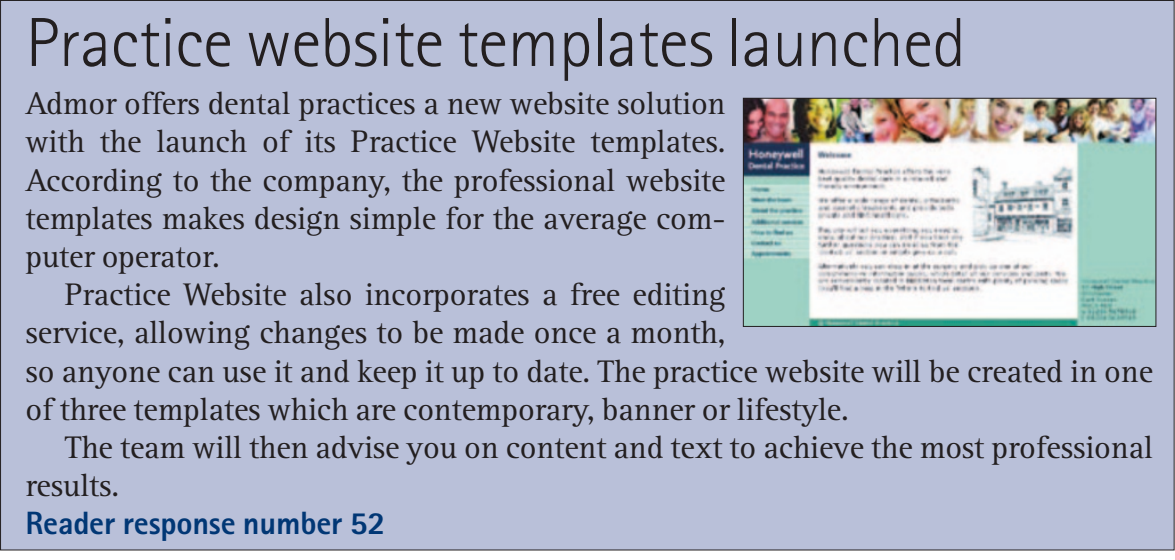

Macleans gets a make-over

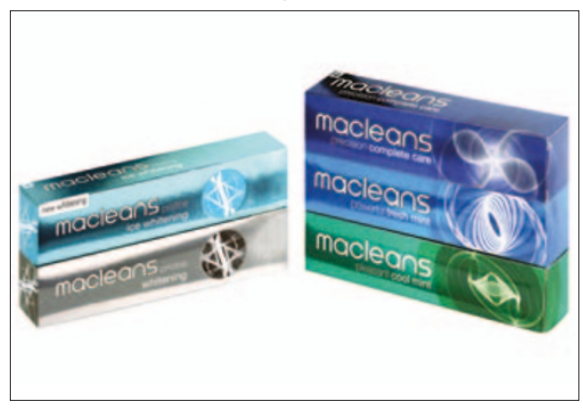

Macleans has a new look which aligns the brand more closely to the burgeoning health and beauty market, it claims. The make-over features new logos, colours, brand icons and health and beauty inspired language.

It hopes the new terminology such as Macleans Powerful Freshmint and Macleans Pristine Ice Whitening will further emphasise the health and beauty message. Reader response number 53 

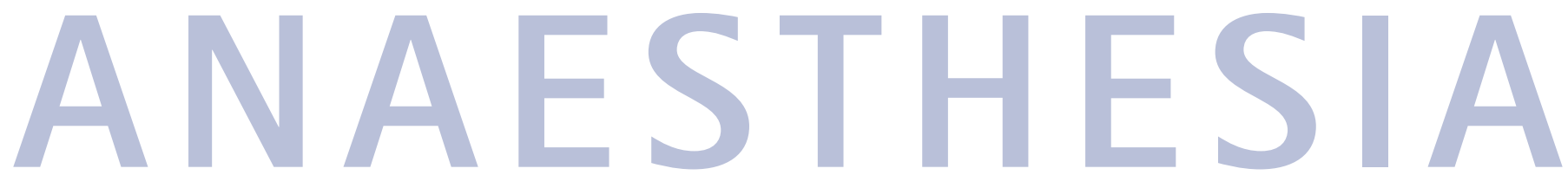

\section{Convenient disposal}

Dentsply Pharmaceutical's Lignostab -A is available in packs of $5002.2 \mathrm{ml}$ cartridges.

The company asserts that it is suitable for routine procedures where vasoconstriction and prolonged anaesthesia (pulpal one hour, soft tissue three hours) is required.

The polypropylene cartridges, can be disposed of in clinical waste as opposed to disposal in sharps bins which can free up space.

Reader response number 54

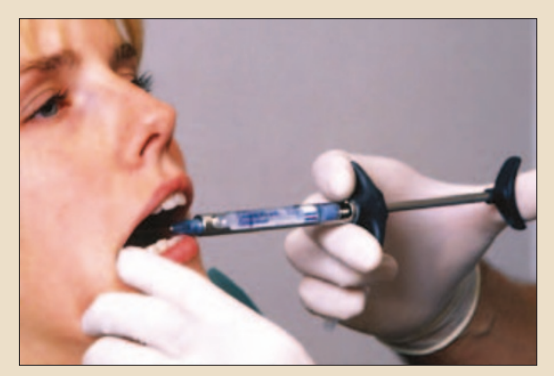

\section{Glass cartridges}

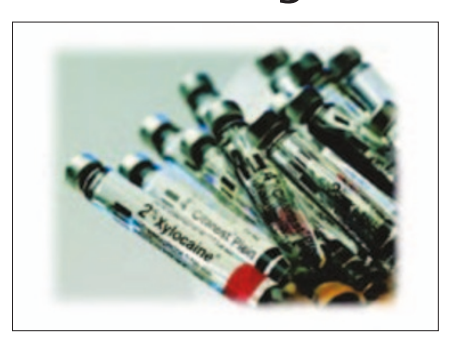

Xylocaine glass cartridges are for use with any injection technique from simple infiltration to intraligamental injections.

Standard cartridges can fit any standard aspirating syringe while self-aspirating cartridges exclusive to Dentsply Pharmaceutical, can be used with self-aspirating syringes with an appropriate, blunt "nipple-ended' plunger. Xylocaine 2\% with Adrenaline $1: 80,000$ is suitable for routine procedures where vasoconstriction and prolonged anaesthesia (pulpal one hour, soft tissue three hours) is required, according to the company.

Reader response number 56

\section{Self-aspiration system}

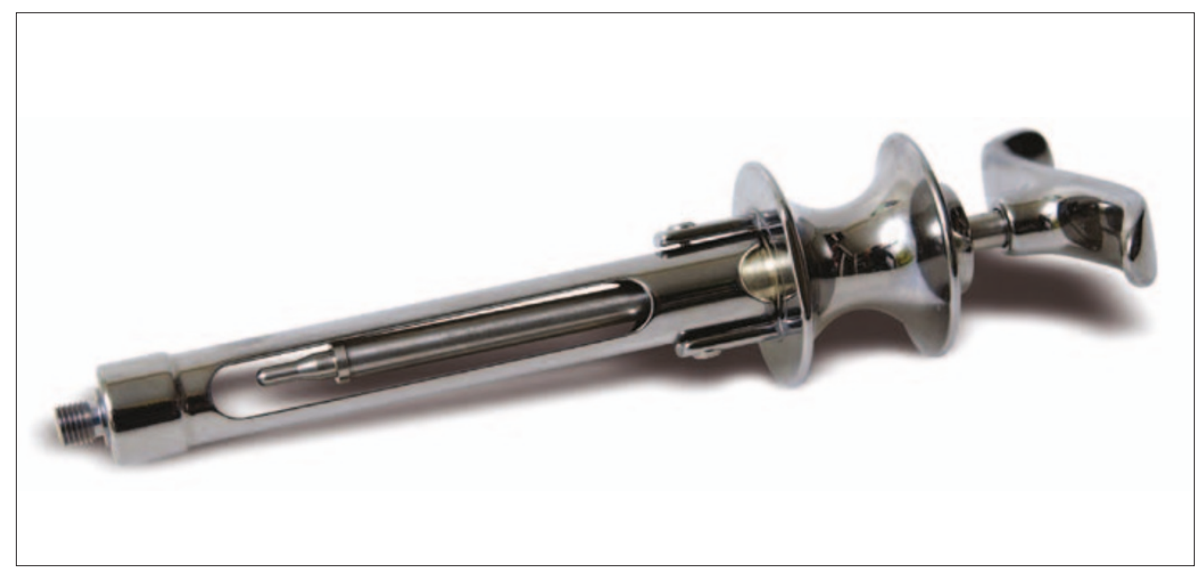

Dentsply Pharmaceutical's self-aspiration system was developed to address the issue of reducing the risk of intravascular injection. The system uses a specific syringe and an adapted cartridge bung with a cavity open at the plunger end. The bungs rely on the elastic nature of a thin membrane at the end of the bung which distorts when pressure is applied.

By releasing the pressure, the bung returns to its normal shape, which is suffi-

\section{Ergonomically designed syringes}

The Paroject syringe from Optident is designed specifically for intra-ligamental (single tooth) anaesthesia and offers immediate onset.

It can be used for simple extractions, primary teeth,

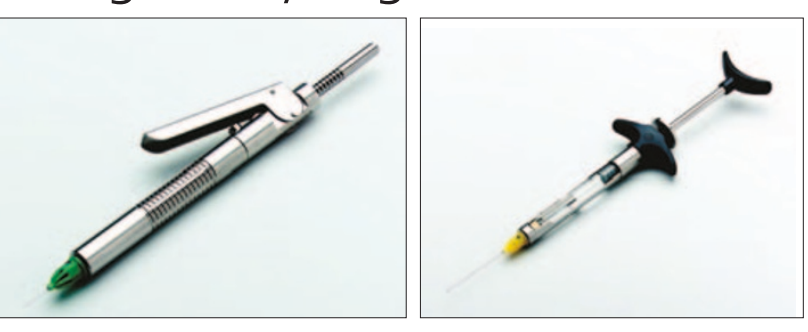
cavity preparations and for endodontic treatments. Manufactured from high grade stainless steel, it is compact with a 'pen-like' design. Paroject can be used to treat teeth in more than one quadrant and offers gentle pain control, due to the small injection dose. It can also replace palatal injections for the treatment of haemophiliac patients. It can be sterilized using any method at a maximum of $200^{\circ} \mathrm{C} / 390^{\circ} \mathrm{F}$ and will accept both $1.8 \mathrm{ml}$ and $2.2 \mathrm{ml}$ cartridges.

The Aspiject syringe is ergonomically designed to offer the dentist a tactile feel from needle tip to the fingertip of the syringe and is manufactured from high-grade (acid resistant) stainless steel and from engineering thermoplast which is resistant to heat and chemical agents.

Sterilizing of the finger grip can be achieved up to $200^{\circ} \mathrm{C}$ and the barrel can be autoclaved up to $135^{\circ} \mathrm{C}$. The Aspiject syringe will accommodate both $1.8 \mathrm{ml}$ and $2.2 \mathrm{ml}$ cartridges that are easily loaded or removed.

Reader response number 57 


\section{No latex or natural rubber}

Citanest 3\% with Octapressin owned by Dentsply, contains no latex or natural rubber and can be used with those patients who have latex allergies, according to the company.

In addition, as an alternative to the standard of lidocaine with adrenaline, Octapressin can offer features more suitable for patients with cases of marked vasolability, a tendency to collapse, vegetative dystonia and known or suspected hypersensitivity to adrenaline.

Dentsply claims the product is also better tolerated by those with heart or blood pressure problems, and is suitable for patients on tricyclic antidepressants and MAOIs.

Citanest is available in boxes of 100 Citanest $4 \%$ injection standard cartridges and Citanest $3 \%$ with Octapressin standard or self-aspirating cartridges are available.

Reader response number 58

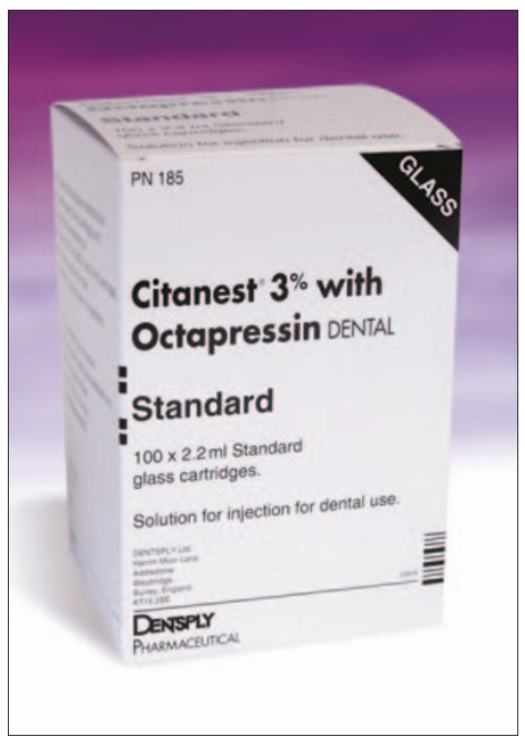

\section{Modern injection technology}

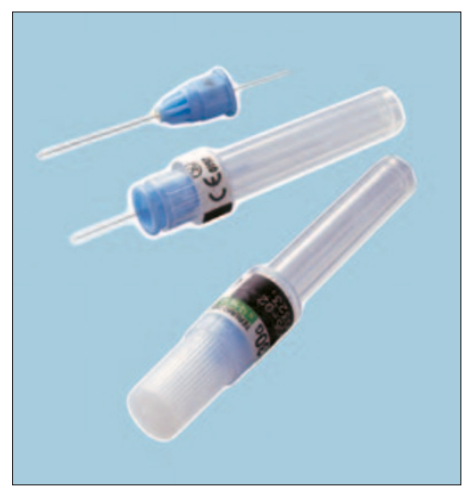

Neolus needles represent the state of the art in modern injection technology according to Terumo. The needles feature an ultrasharp Lancet Point and triple bevel design. Terumo claims that the silicone lubrication allows smooth insertions in and out of multiple sites, without the risk of a break or the discomfort associated with the 'knocking effect' and it has a $12 \%$ wider cannula for smoother flow of anaesthetic.

The needles are individually packed in sterile, colour coded blister packaging with a clear indication of expiry date. Their transparent colour coded hub allows for easy gauge identification and rapid observation of flashback. The moulded, rigid needle protector ensures the integrity of the needle until the moment of use and the needles are guaranteed latex free to avoid allergic reactions. Trycare Ltd stock gauge sizes $27 \mathrm{G}$ long, 30G short and 30G extra short, which are supplied in boxes of 100 and there are additional discounts for those wanting to order a case of 20 boxes.

Reader response number 59

\section{Plastic hub needles}

Dentsply's Hypo EZ-Aim plastic hub needles feature a bevel indicator for correct needle insertion. To reduce the sensation of injection, they have a tri-bevel point for easy tissue penetration without coring and a silicone coating to reduce pain and tissue trauma.

As a latex-free product and package there are no latex allergy problems, the product comes in an extensive size range and is colour-coded for easy identification. The tamper indicating seal provides package integrity and the imperial thread will fit UK and Irish syringes. The needles are available in the widest range of sizes available in the UK (long, short and extra-short, 25, 27 and 30 gauge). Standard Metal Hub Hypo needles are also available, again in a range of long, short and extra-short 25, 27 and 30 gauges.

Reader response number 60

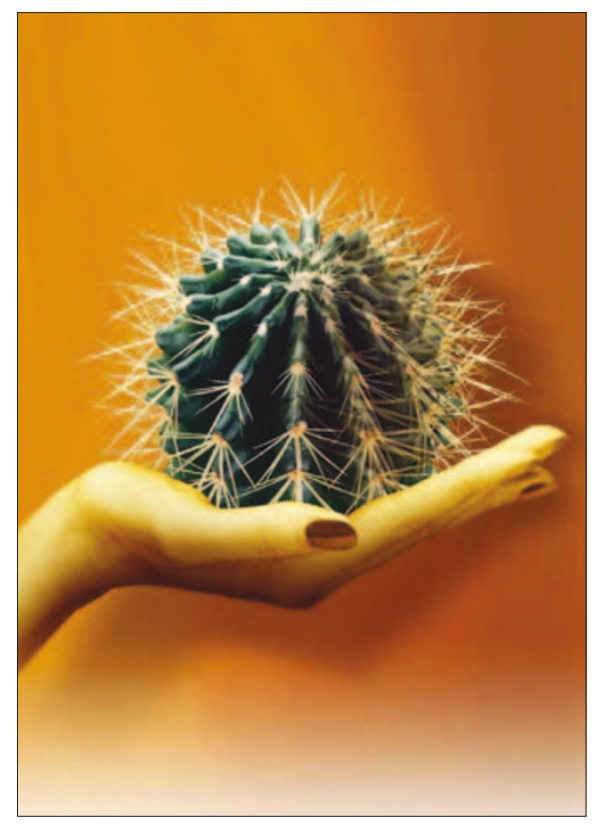

